\title{
Cultural revolution in whale songs
}

\section{Humpbacks have picked up a catchy tune sung by immigrants from a distant ocean.}

Tis: he song patterns of humpback whales (Megaptera novaeangliae) depend on where they live, with populations inhabiting different ocean basins normally singing quite distinct songs. Here we record a unique and radical song change in the song of humpback whales in the Pacific Ocean off the Australian east coast. Their song was replaced rapidly and completely by the song of the Australian west coast population from the Indian Ocean, apparently as a result of the introduction of only a small number of 'foreign' singers. Such a revolutionary change is unprecedented in animal cultural vocal traditions and suggests that novelty may stimulate change in humpback whale songs.

Male humpback whales sing while migrating to and from their breeding grounds, and when they are at the grounds themselves ${ }^{1-3}$. Song is thought to be a form of sexual display, but it is not known whether its main purpose is to repel other males or to attract females ${ }^{2,4}$. All males in a population produce the same song, which changes through time ${ }^{2,3,5}$, and all singers maintain the changes, implying that there is a cultural transmission and evolution as in some bird songs ${ }^{6}$. Songs across an ocean basin are broadly similar - differences increase with distance - but populations in different oceans separated by continents have apparently unrelated songs $s^{3,7}$.

In the austral winter and spring, humpback whales are found along the east coast of Australia ${ }^{3,8}$, calving and mating in the waters of the Great Barrier Reef. Using hydrophones suspended from radio-linked buoys and small boats, we recorded humpback whale songs off southeast Queensland during northward and southward migrations between 1995 and 1998, from which 1,057 hours of song were analysed. In 1995 and 1996, the song pattern changed slightly in an evolutionary fashion. But two singers out of 82 were singing a new, completely different song (Fig. 1). In 1997, the new song became more common. Most of the 112 singers produced either the old or the new song, but three used an intermediate song containing themes from both types. By the end of the 1997 southward migration, almost all males had switched songs, and in 1998 only the new song was heard.

The new song was nearly identical to the song of humpback whales migrating along the west coast of Australia in 1996. West and east coast songs are usually very differ$\mathrm{ent}^{3}$ and there is only a small amount of interchange between these populations ${ }^{8,9}$. The very low incidence of the new song in

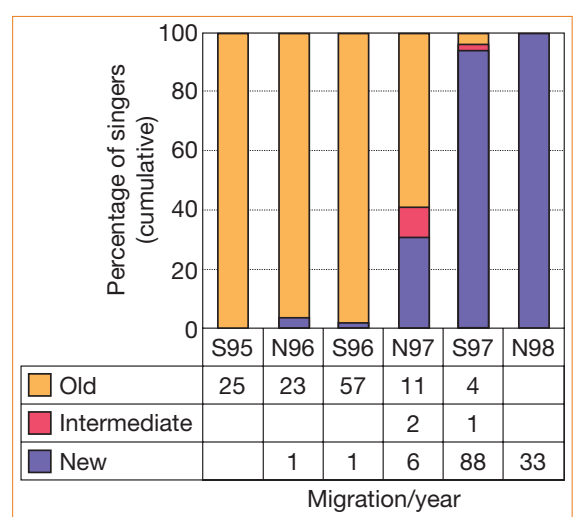

Figure 1 Relative prevalence of different song types in male humpback whales migrating along the east coast of Australia in 1995-98. S, southward; N, northward. The table shows the number of males singing each song type during each migration; the graph shows the relative prevalence of each song type. Most changes in the song patterns occur during the breeding season, when song is being used, and not during the rest of the year when the whales are feeding in high-latitude waters. Over 1,000 hours of song were analysed aurally and spectrographically to determine the song pattern for 252 song bouts.

1996 and the fact that the songs of the two populations evolved independently after 1996 is consistent with the new song being introduced by movement of a small number of singers between populations in 1996.

Humpback whale song shows similarities to song in some birds, particularly the Panamanian yellow-rumped cacique ( $\mathrm{Caci}$ cus cela vitellinus $)^{10}$ and village indigo bird $(\text { Vidua chalybeata })^{11}$, in which song repertoires are colony-specific and all individuals have similar repertoires which change with time. But there are no examples of radical song replacement initiated by a small number of immigrant individuals in these or any other species of songbird.

\section{Alloys \\ A stable binary quasicrystal}

$\Lambda$ ll stable quasicrystals known so far are composed of at least three metallic elements ${ }^{1-4}$. Sixteen years after the discovery of the quasicrystal ${ }^{5}$, we describe a stable binary quasicrystalline alloy in a cadmium-ytterbium $(\mathrm{Cd}-\mathrm{Yb})$ system. The structure of this alloy represents a new class of packing of 66-atom icosahedral clusters whose internal structure breaks the icosahedral symmetry. The binary quasicrystal offers a new opportunity to investigate the relation between thermodynamic stability
The process of change in humpback whale song and bird song has been classified as 'cultural evolution', whereby changes in songs are passed among individuals by learning and accumulate over time ${ }^{6}$. The changes we describe in the song of the humpback whales off the east coast of Australia were cultural in that they were due to the learning of a vocal behavioural pattern and not to a mass influx of immigrants. But the rapid and complete replacement of a complex song over a period of less than two years is revolutionary rather than evolutionary, and suggests that novelty drives changes in humpback whale song. To our knowledge, such 'cultural revolution' is unknown in the vocal cultural tradition of any other animal.

Michael J. Noad ${ }^{\star}$, Douglas H. Cato ${ }^{\star} \dagger$,

M. M. Bryden ${ }^{\star}$, Micheline-N. Jenner‡, K. Curt S. Jennerł

${ }^{*}$ Department of Veterinary Anatomy and Pathology, University of Sydney, New South Wales 2006,

Australia

e-mail:mnoad@mail.usyd.edu.au

$\dagger$ Defence Science and Technology Organisation,

Pyrmont, New South Wales 2009, Australia $\ddagger$ Centre for Whale Research, PO Box 1622,

Fremantle, Western Australia 6959, Australia

1. Payne, R. S. \& McVay, S. Science 173, 585-597 (1971).

2. Winn, H. E. \& Winn, L. K. Mar. Biol. 47, 97-114 (1978).

Cato, D. H. Mem. Queensland Mus. 30, 277-290 (1991).

4. Tyack, P. Behav. Ecol. Sociobiol. 8, 105-116 (1981).

5. Payne, K., Tyack, P. \& Payne, R. in Communication and Behavior of Whales (ed. Payne, R.) 9-57 (Westview, Boulder, CO, 1983).

6. Mundinger, P. C. Ethol. Sociobiol. 1, 183-223 (1980).

7. Winn, H. E. et al. Behav. Ecol. Sociobiol. 8, 41-46 (1981).

8. Chittleborough, R. G. Aust. J. Mar. Freshwat. Res. 16, 33-128 (1965).

9. Baker, C. S. et al. Mar. Mamm. Sci. 14, $721-737$ (1998).

10. Trainer, J. M. Ethology 80, 190-204 (1989).

11.Payne, R. B. Z. Tierpsychol. 70, 1-44 (1985).

and quasiperiodic structure, as well as providing a basis for the construction of crystallographic models.

We have previously ${ }^{6,7}$ prepared quasicrystals in alloys of the Cd-Mg-RE type (where RE is a rare-earth metal) by annealing. We systematically eliminated the magnesium component and tested the effect on the phase diagram of the $\mathrm{Cd}-\mathrm{Yb}$ system. In doing so, we discovered an unknown phase with a congruent melting point of $636^{\circ} \mathrm{C}$ at a composition of $\mathrm{Cd}_{57} \mathrm{Yb}$ (where $\mathrm{Yb}$ was 15 atom $\%)^{8}$. We prepared this alloy of $\mathrm{Cd}_{5.7} \mathrm{Yb}$ by using an induction furnace and solidified it in an aluminium oxide crucible under an argon atmosphere.

Single crystals of $\mathrm{Cd}_{57} \mathrm{Yb}$ have an 
orthogonal unit cell with very large edges, but they did not correspond to any known structure ${ }^{9}$. The powder X-ray diffraction pattern obtained from this alloy identified it as a quasicrystal, and selected-area electrondiffraction patterns verified it had a primitive icosahedral lattice. The quasicrystalline phase was evident in the solidified as well as in the fully annealed state, indicating that the quasicrystalline phase is thermodynamically stable. To our knowledge, this is the first evidence of a thermodynamically stable quasicrystal in a binary system. Unlike all other stable quasicrystals, which show incongruent melting, this new stable quasicrystal has a congruent melting point, as can be seen from the phase diagram ${ }^{8,9}$.

Figure 1a shows transmission Laue Xray diffraction patterns taken with incidence along 5-fold, 3-fold and 2-fold axes from a single quasicrystal of size $0.2 \mathrm{~mm}$ extracted from the as-cast alloy. The patterns show many sharp reflections with 5-fold, 3-fold and 2-fold symmetry, indicative of a highly ordered quasiperiodicity with icosahedral symmetry persisting over a long range.

The structures of $\mathrm{Al}-\mathrm{Mn}$ and $\mathrm{Al}-\mathrm{Zn}-\mathrm{Mg}$ quasicrystals can be deduced from their crystalline approximant structures $\alpha-\mathrm{Al}-\mathrm{Mn}-\mathrm{Si}$ and $(\mathrm{Al}, \mathrm{Zn})_{49} \mathrm{Mg}_{32}$, respectively ${ }^{10,11}$. (A crystalline approximant is a phase whose composition is close to or identical to that of a quasicrystal and whose unit cell has atomic decorations that look like a quasicrystal, such as icosahedral clusters of atoms, but which is nonetheless a crystal.) Similarly, the structure of our new quasicrystal can be understood by reference to the compound
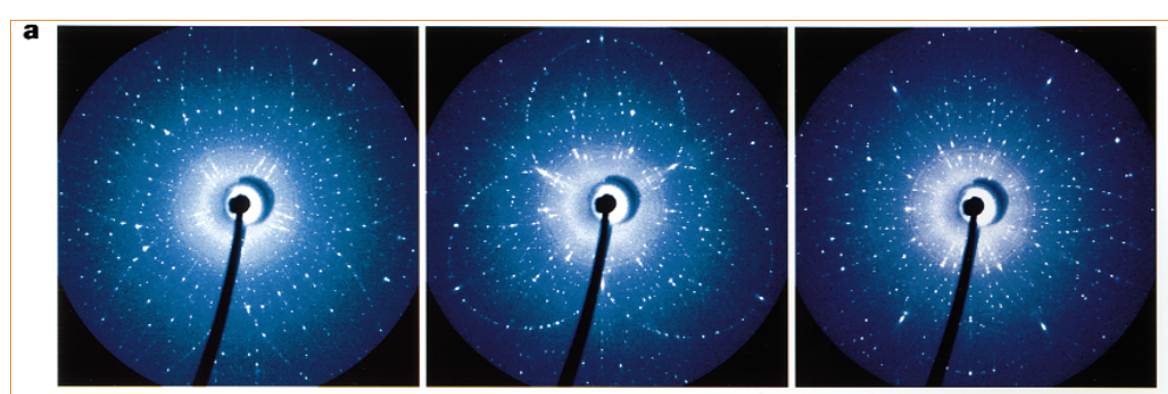

b
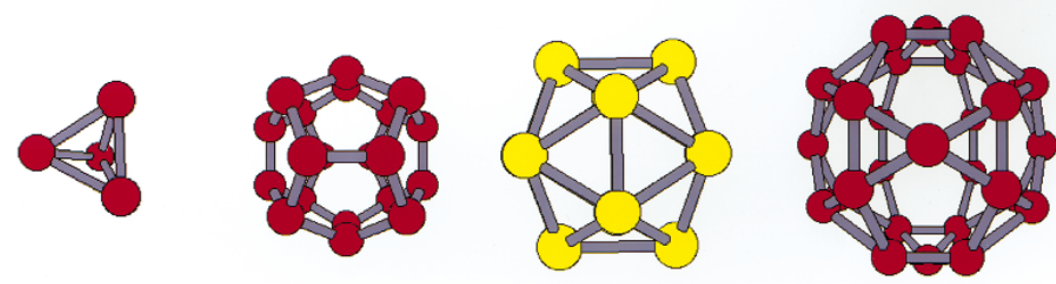

Figure $1 \mathrm{Cd}_{5.7}$ Yb quasicrystal. a, Transmission Laue X-ray diffraction patterns along 5-fold, 3-fold and 2-fold axes (respectively, left to right) from a single quasicrystal. Based on its orientation, the quasicrystal was confirmed to have icosahedral symmetry. Patterns were obtained from a single grain, indicating that the quasicrystal structure is stable enough to create a bulk form. $\mathbf{b}$, Decoration of the icosahedral cluster in the quasicrystalline $\mathrm{Cd}_{5.7} \mathrm{Yb}$ alloy, as deduced from the cubic $\mathrm{Cd}_{6} \mathrm{Yb}$ crystalline approximant. The first shell is created by four $\mathrm{Cd}$ atoms around the cluster centre, the second consists of 20 atoms forming a dodecahedron, the third is an icosahedron of $12 \mathrm{Yb}$ atoms, and the fourth is a $\mathrm{Cd}$ icosidodecahedron obtained by placing $30 \mathrm{Cd}$ atoms on the edges of the $\mathrm{Yb}$ icosahedron. In all, the icosahedral cluster consists of 66 atoms. Cd, red atoms; Yb, yellow atoms. can build up to form a bulk quasicrystal remains an open question.

\section{A. P. Tsai, J. Q. Guo, E. Abe,}

\section{H. Takakura, T. J. Sato}

National Research Institute for Metals, and CREST, Japan Science and Technology Corporation,

Tsukuba 305-0047, Japan

\section{e-mail:aptsai@tamamori.nrim.go.jp}

1. Ball, M. D. \& Lloyd, D. J. Scripta Metall. 19, 1065-1068 (1985).

2. Tsai, A. P., Inoue, A. \& Masumoto, T. Jpn J. Appl. Phys. 26, 1505-1507 (1987).

Tsai, A. P., Inoue, A., Yokoyama, Y. \& Masumoto, T. Mater. Trans. Jpn Inst. Metals 31, 98-103 (1990).

4. Tsai, A. P. et al. Phil. Mag. Lett. 70, 169-204 (1994).

5. Shechtman, D., Blech, I., Gratias, D. \& Cahn, J. W. Phys. Rev. Lett. 53, 1951-1953 (1984).

6. Guo, J. Q., Abe, E. \& Tsai, A. P. Phil. Mag. Lett. (in the press).

7. Guo, J. Q., Abe, E. \& Tsai, A. P. Jpn J. Appl. Phys. 39, L770-L771 (2000).

8. Massalski, T. B., Okamoto, H., Subramanian, P. R. \& Kacprzak, L. (eds) Binary Alloy Phase Diagrams 2nd edn, Vol. 2, 996 (ASM International, Gaithersburg, 1990).

9. Palenzona, A. J. Less-Common Met. 25, 367-372 (1971).

10. Elser, V. \& Henley, C. L. Phys. Rev. Lett. 55, 2883-2886 (1985).

11. Henley, C. L. \& Elser, V. Phil. Mag. Lett. B 53, L59-L66 (1986).

\section{Development}

\section{DNA methylation in Drosophila melanogaster}

ertain cytosine residues of eukaryotic DNA are methylated in inactive regions of the genome. For a long time the fruitfly Drosophila was thought to be an exception ${ }^{1-4}$, but now the evidence points to the existence of a functional DNA-methylation system in Drosophila as well $^{5-9}$. Here we show that DNA is methylated, but that Drosophila genomic methylation is restricted to the early stages of embryonic development.

We analysed genomic DNA from Drosophila melanogaster embryos $(0-4 \mathrm{~h}$ old) by high-performance liquid chromatography (HPLC), which revealed a weak signal for 5-methylcytosine (Fig. 1a), consistent with low levels of DNA methylation.

We then analysed genomic DNA at different stages of development by nearestneighbour analysis and thin-layer chromatography. We investigated the methylation of $\mathrm{CpG}$ dinucleotides at DNA sites cut by the restriction enzyme FokI (specific for the sequence GGATGN $_{9-13}$ ) and found a weak signal from embryonic DNA (Fig. 1b; Table 1).

Extension of nearest-neighbour analysis to non-CpG methylation revealed a distinct 5-methylcytosine spot in embryonic-DNA preparations (Fig. 1c). Most methylation was seen at CpT, with some at $\mathrm{CpA}$ and CpC (Table 1). Genomic DNA methylation was prevalent in young $(1-2 \mathrm{~h})$ embryos (Fig. 1c), but less marked in older (15-16 h) embryos (Fig. 1d); only trace amounts of 5 -methylcytosine were found in isolated ovaries (Fig. 1e). We confirmed these results by using a different restriction 